\title{
CNOP Regimen
}

National Cancer Institute

\section{Source}

National Cancer Institute. CNOP Regimen. NCI Thesaurus. Code C63453.

A regimen consisting of cyclophosphamide, mitoxantrone, vincristine and prednisone used to treat both indolent and aggressive forms of non-Hodgkin lymphoma. 